\title{
EVALUATION OF SATISFACTION LEVEL AMONG EMPLOYEES OF HAYDOM INSTITUTE OF HEALTH SCIENCES (HIHS)
}

\author{
Crescent D. Ombay Phd ${ }^{1}$, Mary M. Akonaay MSc ${ }^{2}$, Fanuel M. Axwesso MD ${ }^{3}$, \\ Bartholomayo P. Madangi BSc ${ }^{4}$ \\ ${ }^{1}$ Head department of nursing; Haydom Institute of Health Sciences \\ ${ }^{2}$ Quality Officer; Haydom Institute of Health Sciences \\ ${ }^{3}$ Vice Principal; Haydom Institute of Health Sciences \\ ${ }^{4}$ Principal; Haydom Institute of Health Sciences
}

Article D0I: https://doi.org/10.36713/epra8860 DOI No: $10.36713 /$ epra8860

ABSTRACT

This mini survey is aiming at collecting communal idea and feeling of employees towards their institute and operational modes of different modalities. Through the result from this survey, the management may make conform of the issues suggested by participants basing on the institute existing situation. The survey contemplated on the evaluating level of employees' job satisfaction. All professional employees were invited to participate in the survey and the data was conveniently collected from 22 participants through structured questionnaire (Likert scale). The main areas addressed in the survey were employee job recognition, employee work environment, salary and wages, employee supervision at work.

The results from the survey indicate that majority $(86 \%)$ of the employees are satisfied with the manner they are recognized by the institute management. Most of the employees were satisfied with working environment. However, majority $(82 \%)$ were dissatisfied with amount of salary and wages paid for their work. The survey team recommends the institute management to maintain admirable those areas with high level of satisfaction and take action for those areas with low satisfaction. However, large survey may be needed to observe other areas of satisfaction and dissatisfaction.

KEY WORDS: Employees Job Satisfaction Level

\section{SECTION ONE: INTRODUCTION}

\subsection{Background}

Job satisfaction is the feeling and perception of a worker regarding his/her work and how he or she feels well in an organization. It indicates the extent of employees' positive or negative feelings towards their jobs and organization. According to the study by Lee \& Lin, (2014), job satisfaction relates to the total relationship between an individual and the employer for which he/she is paid. In other hand, job dissatisfaction brings an absence of motivation at work. Researchers in a different way have portrayed various factors contributing to job satisfaction and job dissatisfaction.

Hoppock (1935) was the first who brought forth the concept of job satisfaction in attention. He held that job satisfaction was a combination of psychological, physiological and environmental circumstances that caused a person to say that "I am satisfied with my job". On view of Spector, (1977); job satisfaction means employee's emotion to the extent of like and dislikes of his or her job. According to Thiagaraj\& Thangaswamy (2017), study, the highly satisfied employees will exert extra effort and contribute positively to the effectiveness and efficiency of their organizations. Job satisfaction will lead to better performance and the employees will be more committed towards their organization. 


\section{Factors for Job Satisfaction}

Some variables responsible for job satisfaction of bankers and other authors are Job status \& security, management policy, pay, working condition, decision making process \& communication pattern, supervisor behavior, job nature, recognition \& promotion. It is evident from many studies reported that better payment; Recognition \& Promotion and Working Condition are strongly co-related to overall job satisfaction (Heywood \& Wei 2006, Anin et al 2015, Aziri 2011, Yusoff et al 2013). However, most of researchers are cumulatively accepting on other top ten factors which are predominantly affecting satisfaction of the employees at any given organization. These include:-

Appreciation for your work, good relationships with colleagues, good work-life balance, and good relationships with supervisors, company's financial stability, learning and career development' job safety and security, attractive fixed salary, working environment and fair Policies and practice.

\section{Various Models for Job Satisfaction}

Frederick Herzberg theorized that employee satisfaction has two dimensions: "hygiene" and "motivation". Hygiene factors include salary, supervision and working environment while Motivation factors include recognition, achievement and work itself; where both of which result to workers more productive, creative and committed (Yusoff et al, 2013). This study further described that hygiene factors remove the dissatisfaction element among the employees while the motivational factors ultimately lead to satisfaction.

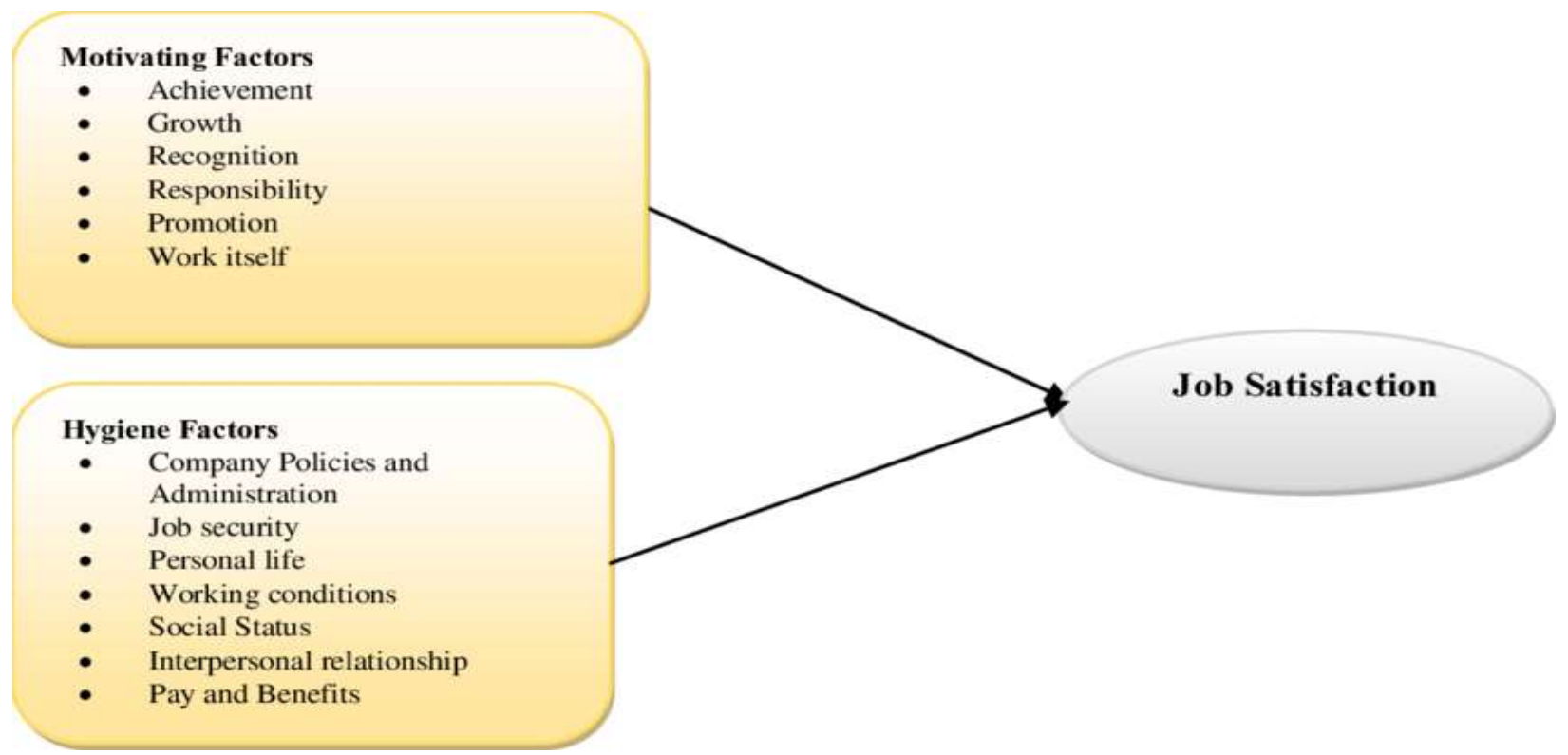

Figure 1: Frederick Herzberg job satisfaction model

In many literatures, opposite of the satisfaction is dissatisfaction; and the lack of those factors for satisfaction is true about causes of job dissatisfaction and unhappiness among staff (Heywood \& Wei 2006, Anin et al 2015, Aziri 2011, Yusoff et al 2013). This situation results into Poor workplace relationships, denial of empowerment or influence among workers, lack of work-life balance, feeling unappreciated and others.

The negative outcome of staff dissatisfaction is significantly unfastened to the institute. Maniram (2007) states that, if job satisfaction is not well observed, it may lead to poor productivity, high absenteeism, and turnover among the staff. 

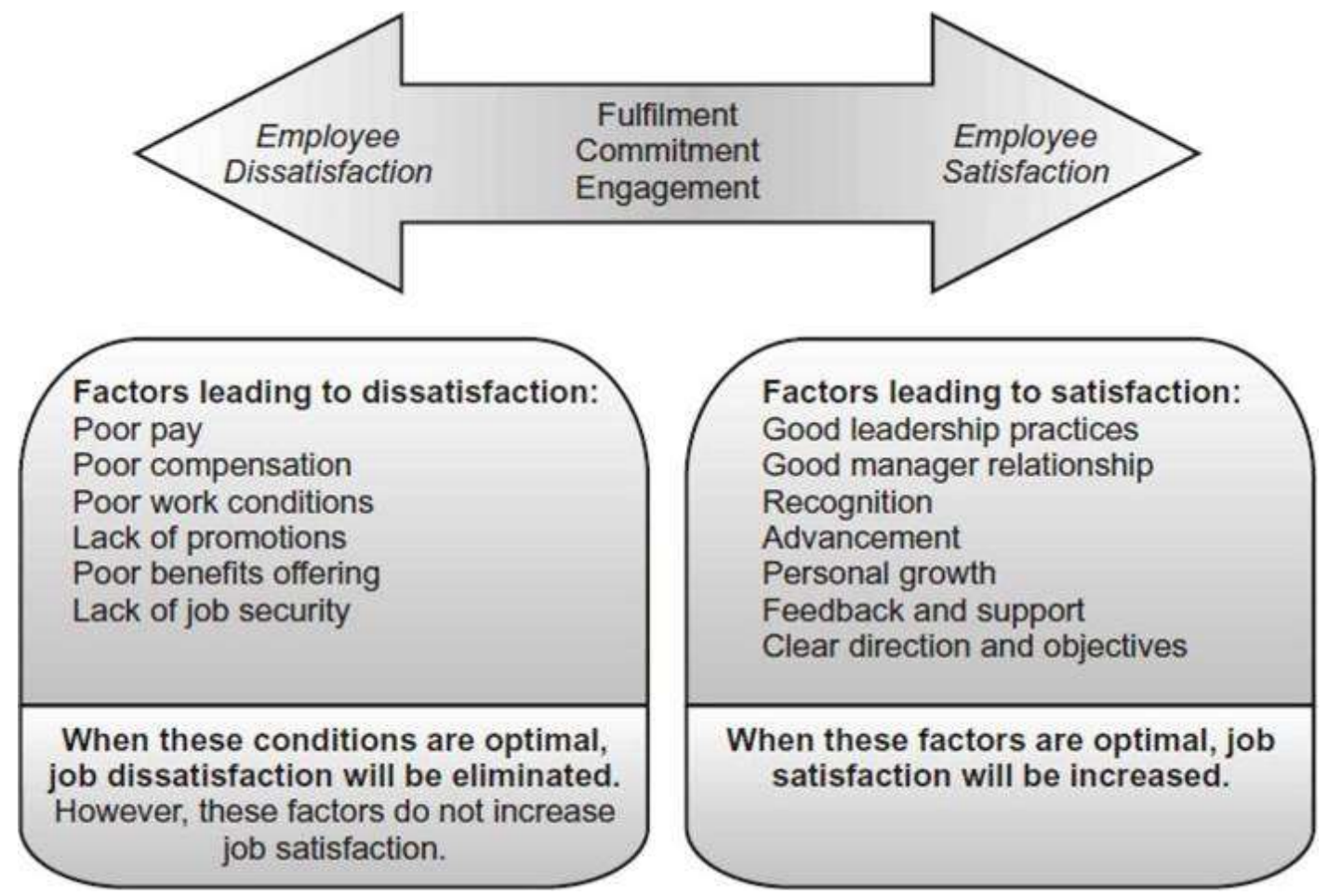

Figure 2: satisfaction and dissatisfaction model

As from the review of many literatures, all possible efforts and strategies done to improve workers satisfaction are also those cut across maintaining employees' retention to the job(Heywood \& Wei 2006, Anin et al 2015, Aziri 2011, Yusoff et al 2013).

\subsection{Statement of situation}

Haydom Institute of Health Sciences (HIHS) is a faith based organization that deals with delivery of health training to the health professionals. The institute is a long standing organization located in a remote area of Manyara region with a community diverse socio-cultural background. The institute is estimated to have total number of 30 full time academic staff and 15 other supporting staff. Like it happens in other institutes, employees' satisfaction is a matter of concern at HIHS. However, in general; the institute is aware of the negative impacts of job dissatisfaction among its staff and institute; and in many times, it had tried several efforts to enhance job satisfaction by imposing various staff retention strategies. These efforts include establishment of different policies on compensation or remuneration and salary payment, offer of meals/teal, payment of different allowances including teaching, housing and travel allowance. In particular, the institute offers supports to those who need learning and career development every year basing on institute priorities. Furthermore, the institute provides working office to academic staff and other supporting staff

Despite all these efforts above, it is still evident that a number of its employees leave the institute for searching a greener pastures. The morale of many workers seems down as it is evidenced by low commitment to their work. The productivity of the works seems low in term of academic performance of the students. Yet, the reasons for those episodes are not clearly revealed. For this reason, the institute aimed at conducting a mini survey to investigate job satisfaction level among its staff. Among others, the survey addressed the key satisfier factors including work environment, Recognition, task itself and job security, supervision and Salary and wages

\subsection{Significance of doing mini survey}

Low job satisfaction levels can impact the bottom-line of institute in a number of ways. Here are some of them. Because unsatisfied workers don't like their jobs, it's impossible for them to become fully productive. Unsatisfied workers can become toxic over time, which could seriously hurt employee morale, pollute your work environment, and increase turnover. Unsatisfied workers may take their bad attitude out on institute customers, adversely affecting the institute brand's reputation. When institute has many unsatisfied team members on its payroll, 
it's nearly impossible to attract top talent. These surveys can be administered electronically and anonymously to ensure employees are able to share their view and thoughts without fear of retribution.

\section{4. objectives}

The specific objectives for the survey were:-

To evaluate the employees job recognition at HIHS

Assess employees' satisfaction on working environment at HIHS

Identify satisfaction level of employees on payment and incentives

To determine satisfaction level of employee on supervision at work by leaders

\section{SECTION TWO: METHOD OF DATA COLLECTION}

All professional employees from HIHS were included in this mini survey. A modified structured questionnaire with a Likert rating scales was adapted and administered to the employees and data was conveniently collected. The degree of satisfaction was measured by Likert rating scales with range of $1=$ Strongly Disagree, $2=$ Disagree, $3=$ neutral, $4=$ agree, $5=$ strongly agree. The data analysis was done by SPSS 20 version software program

\section{SECTION THREE: RESULTS}

\section{Introduction}

The participants involved in this mini survey were 24 whereas all of them were professionals from various cadres in deferent departments of HIHS. Of this number, two of them, their questionnaires were incomplete. The main variables involved were recognition of employees, working environment of the employees, salary and wages and employees supervision at work. The results are summarized in the tables and figures below.

\subsection{Job recognition}

In this variable, participants were provided with several statements to see if they are satisfied with the manner the management recognizes them in different aspects of their works. The statements involved were:-

I am noticed when I do a good job

Recognition is given for group achievement

I am recognized by my leader for the work I do

I am appreciated by my peers

I am given appropriate rewards on the job

The results are displayed in the figures bellow

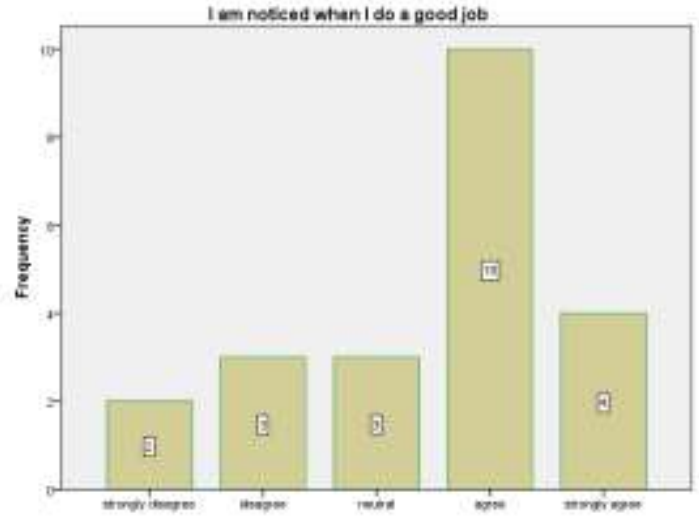

Figure 3a; Recognition for good job

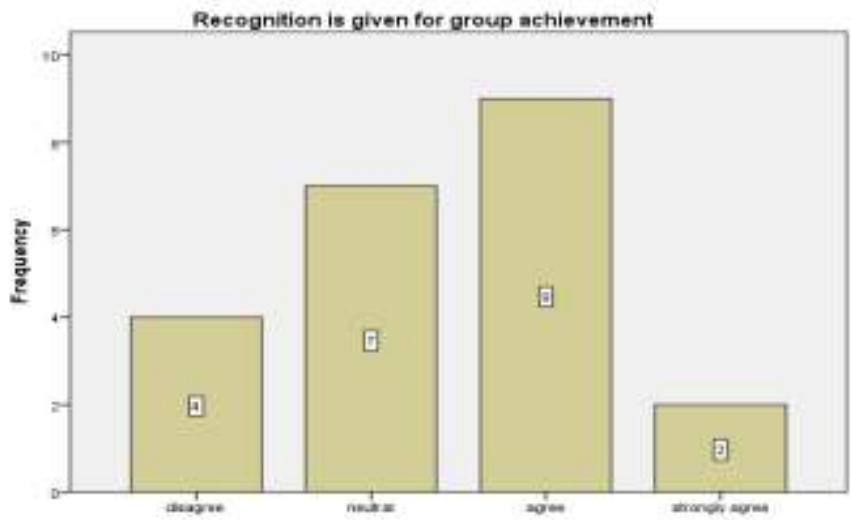

Figure4b: Recognition for group achievement 

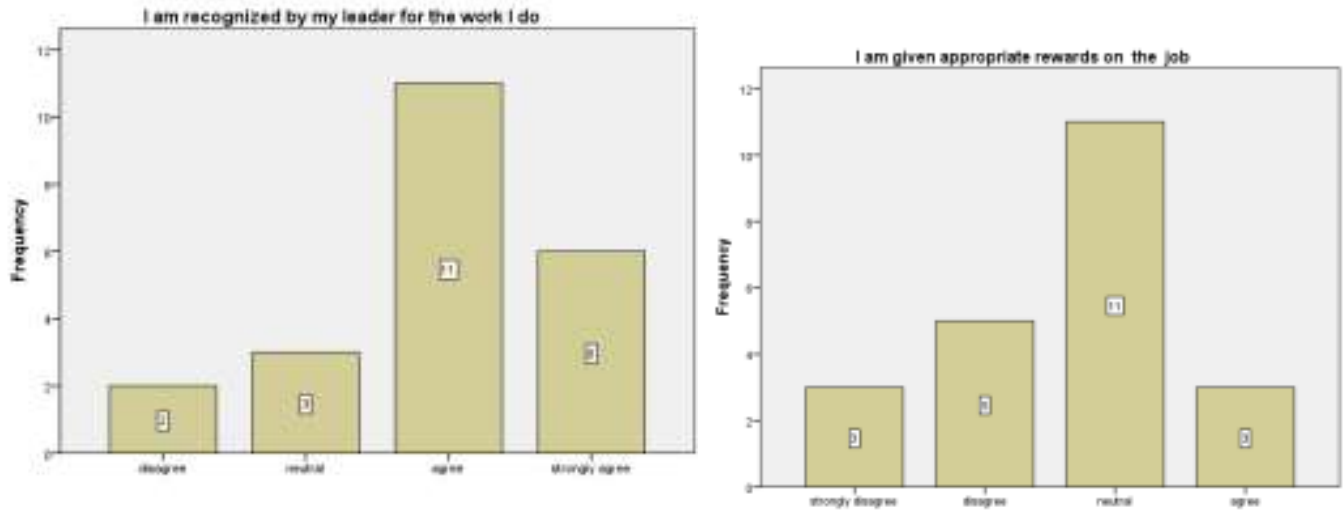

Figure 4a: Recognition by leader

Figure 5b; Appreciation by rewards

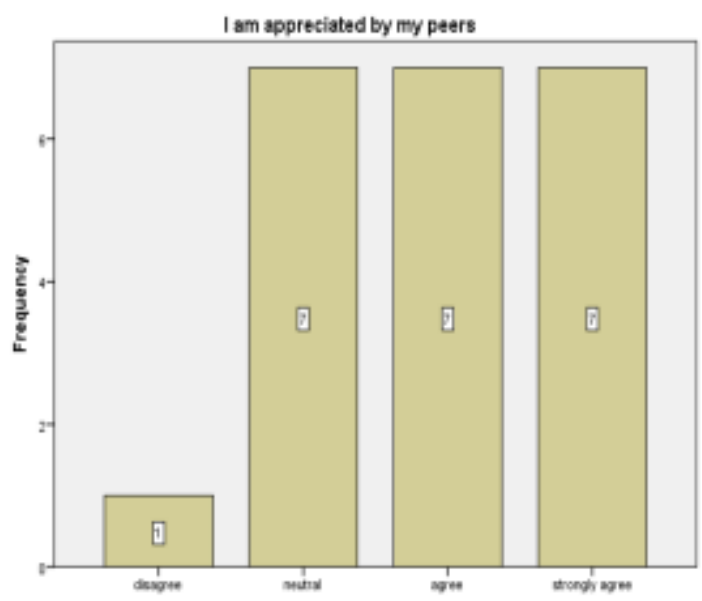

Figure 5: Appreciation by peer group

According to the most components of the recognition variable, majority of the employees seem to agree and satisfied that they are recognized by the management in different aspects of their works.

Through the statistical analysis, the likert rating scales has total of 25 responses. The overall results of the recognition variable were summarized into equal two categories; "Not recognized (5 - 12 score) and Recognized (13 -25 score)" as it is shown in the below figure

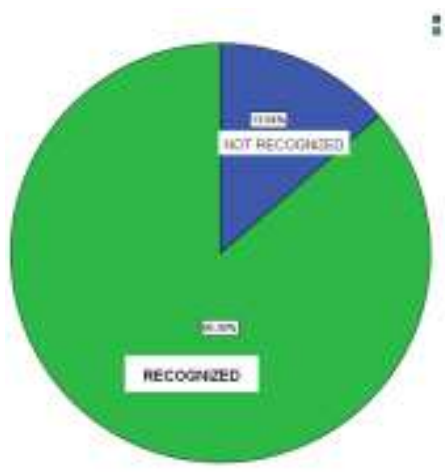

Figure 6: Total employees Recognition 
As conclusion of this variable; majority $(86 \%)$ of the employees were satisfied with the manner the management recognizes them in different aspects of their works.

\subsection{Working Environment}

The second area that the survey captured was employees' Working environment. Participants were asked to respond to the statements that signify whether they are satisfied or not against their working environment as shown bellow:-

I work in a safe, healthy and comfortable environment

I like my work environment

Materials and equipment I work with are adequate and available every time

I have my working office

Being in remote and rural dissatisfy me

I have secured future outcome of my work

Statistical analysis of the likert rating scales has total of 30 responses. The overall results of the survey on the variable "working environment" were summarized into two equal categories; "Dissatisfied (5 - 15) and Satisfied (16 - 30) with working environment as shown in figure 8 below. The study revealed that all participants satisfied with working environment.

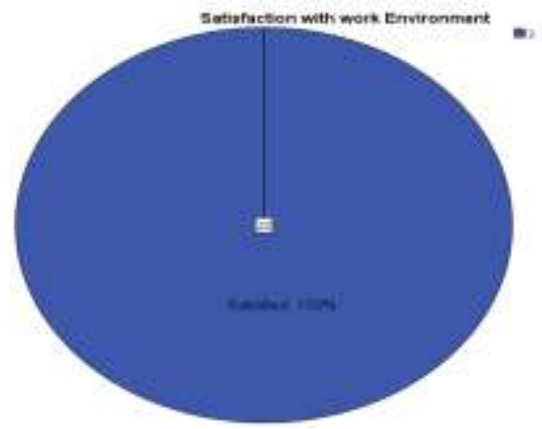

Figure 7: Total satisfaction with working environment

On the variable "Working Environment" basing on the statistical results above, average satisfaction level fall above rating scales of $5-15$ which is dissatisfied.

With this result, the employees at HIHS are satisfied with their Working Environment at $100 \%$. However, some individual components of the variable should not be undermined as they indicate degrees of dissatisfaction.

\subsection{Salary and wages}

Another area that the survey was confined to was salary and wages. Participants were inquired to respond to the statements that collect their suggestions on whether they satisfied with salary and wages that they earn from the institute. The major statements raised were:-

I am satisfied with my health benefits

My payment corresponds with the amount of work I do

I am satisfied with my current salary

My salary compares with others or government scale

I am satisfied with other payment out of salary

I may earn more than here if I would work somewhere else

The results are shown in the bellow figures:- 


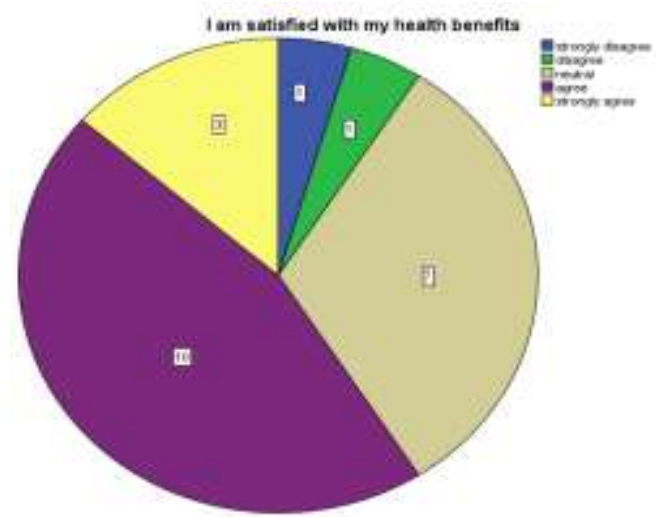

Figure 8a: Satisfaction with health benefits

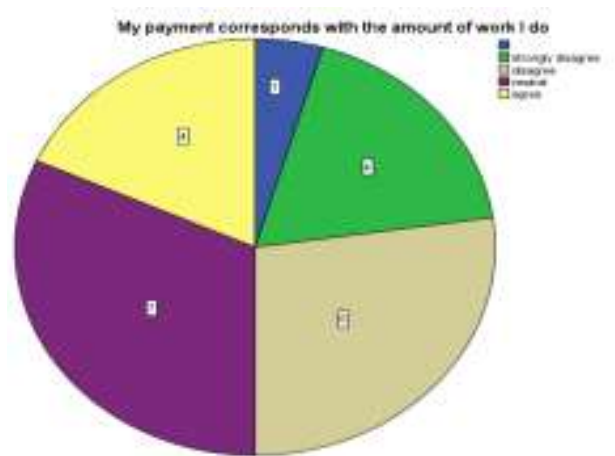

Figure 9b: Payment vs. work

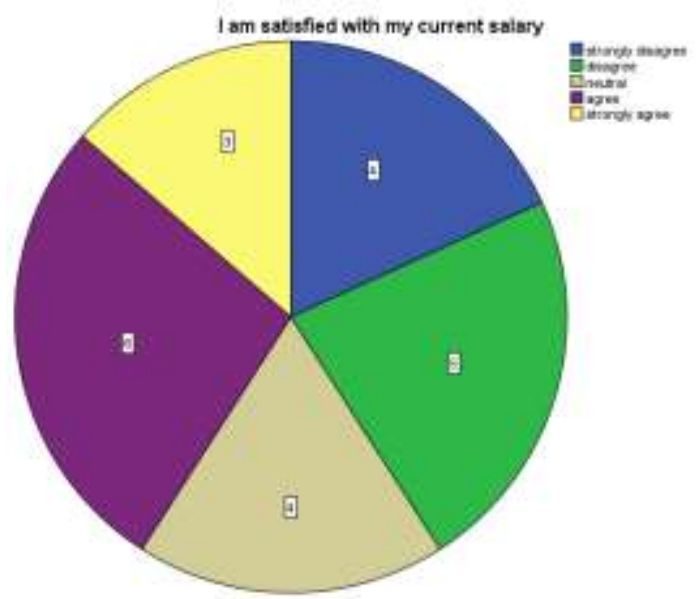

Figure 9a: Satisfaction with current salary

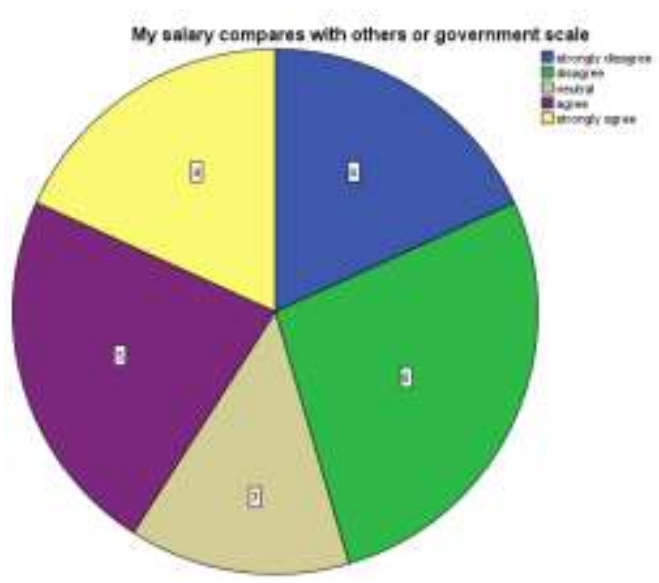

Figure10b: Comparison of salary scales
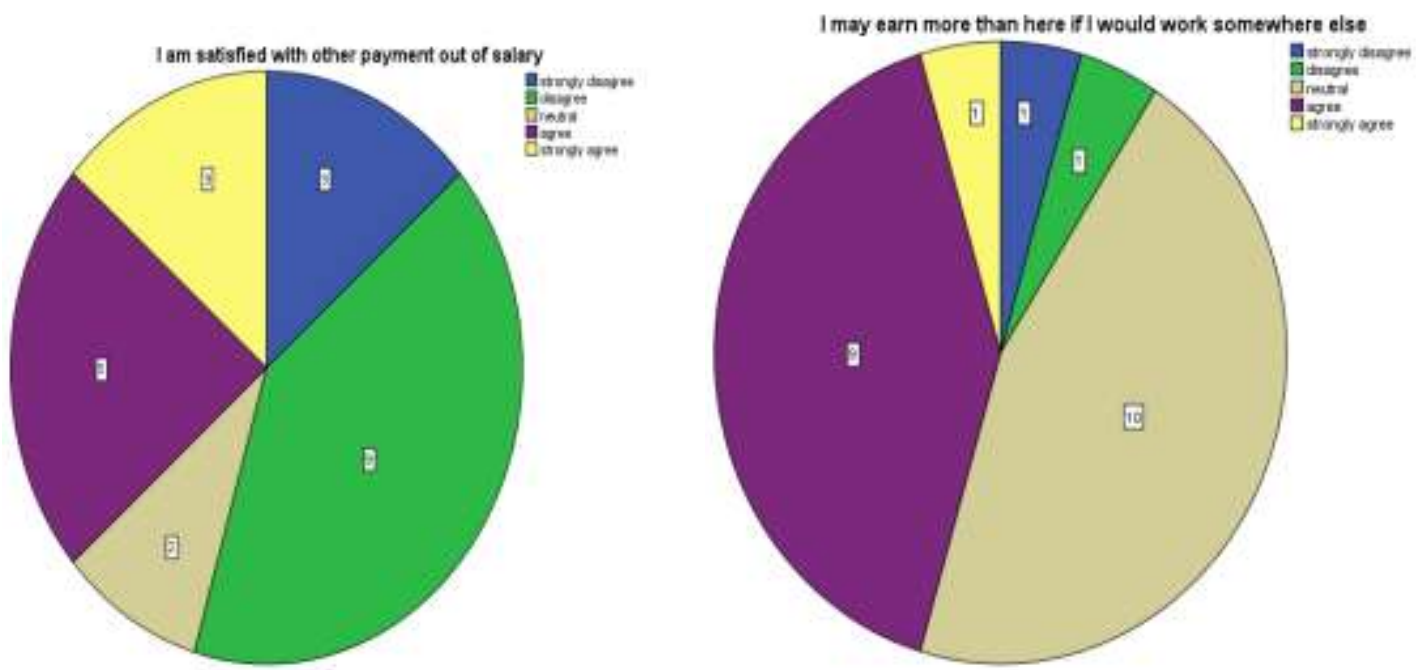

Figure 10a: satisfaction vs. other payment Figure 11b: Earning out of HIHS 


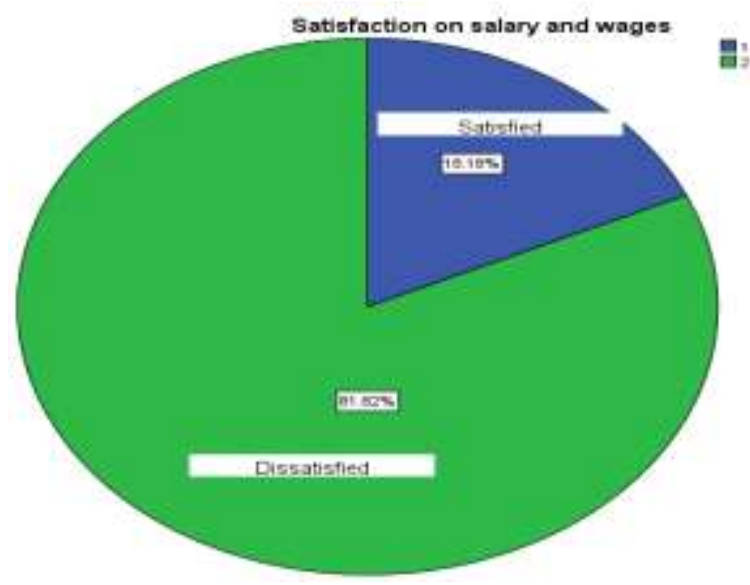

Figure 11: Total satisfaction on salary and wages

In most of the components involved in the survey of the variable "salary \& wages satisfaction", majority were noted to be dissatisfied with salary \& wages paid by the institute. The overall result indicates that, $82 \%$ of the employees were dissatisfied with payment and incentives paid to them. Figure 12 above summarize this result

\subsection{Supervision of employees}

One more area where the survey was addressed to is a supervision of employees by the leaders. Participants were requested to respond to the statements to collect their idea about the manner the leaders' conducts supervision towards employees. The chief statements involved in this area were:-

My leader has good personal relationship with employees

My leader takes care of complaints brought to him appropriately

I have freedom to use my own judgment on my work

My personal needs and wants are taken care of by management

The results are displayed in the figures below:-

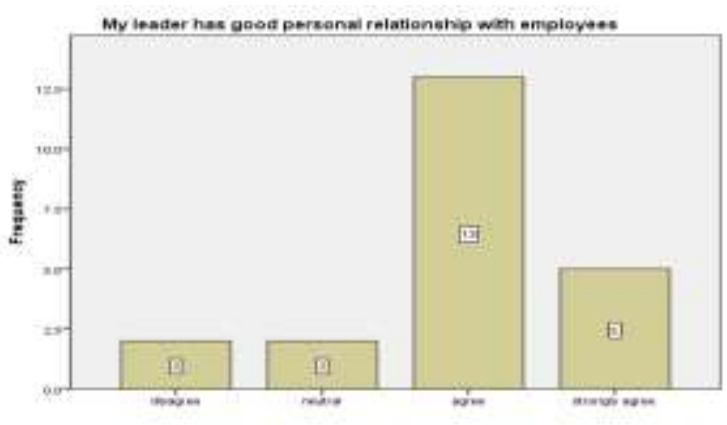

Figure 13a: Leaders interpersonal relation

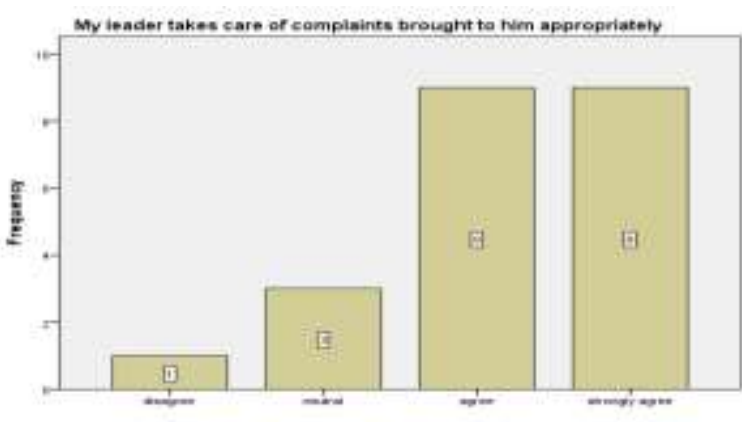

13b: Leaders care of complains 


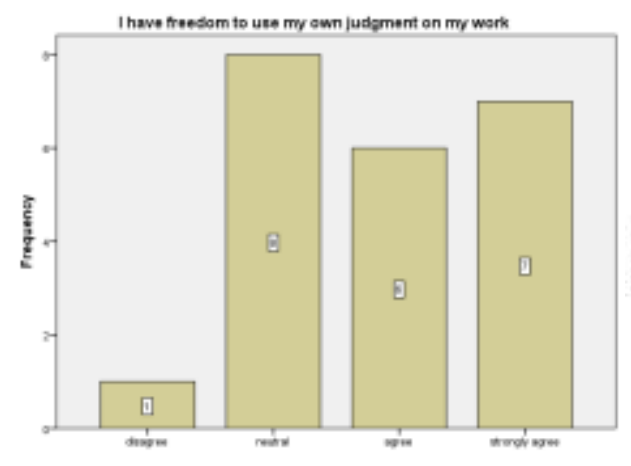

Figure 14a: Freedom on work



Figure 14b: Care of personal needs

On the supervision variable, majority of the employees were satisfied with the manner leaders conduct supervision upon their subordinates. This is more significant when the result is statistically categorized into either satisfied or dissatisfied. The figure and table below summarizes the findings

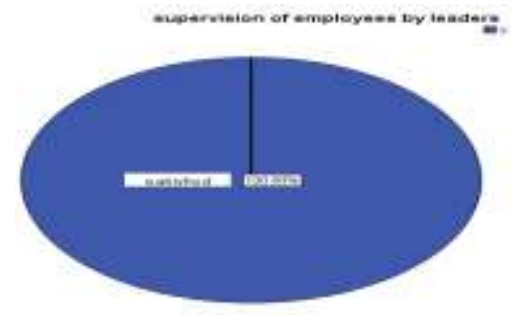

Figure 15: total satisfaction on supervision of employees

\section{CONCLUSION AND RECOMMENDATION}

Job satisfaction is the feeling and perception of a worker regarding his/her work and how he or she feels well in an organization. There is direct relationship between employees' satisfaction and job performance. Low job satisfaction levels can impact to the bottom-line of institute in a number of ways. Job satisfaction instead tends to lead to the better performance as the employees are more committed towards their organization.

In this mini survey, employees were satisfied with their working environment. In other area, employees were satisfied with the way the management recognizes them in different aspects of their works. Moreover, the employees are satisfied with the manner their leaders conduct supervision upon their subordinates. However, in the area of payment and incentives, majority of the employees are dissatisfied with amount of salary and remuneration paid for their work.

The surveyor team recommends that the institute management to maintain upbeat and worthy full efforts towards those areas with high level of satisfaction and take actions into consideration for those areas with low satisfaction. These precious efforts and actions may result in significant reduction of employees' turnover, duty absenteeism and long-term human resource costs. It may further result into an increase of institute productivity, employees' retention and fostering an environment that cultivates and retains talented staff. The team however, recommends the institute to conduct a large survey that involves other areas of satisfaction and dissatisfaction to improve employees' job affairs.

\section{REFERENCES}

1. Aziri B. (2011), Job Satisfaction: A Literature Review; Management Research and Practice vol. 3 issue 4 pp: 77-86, Tetovo, Makedonia

2. Thiagaraj D. \& Thangaswamy A. (2017), Theoretical Concept of Job Satisfaction - A Study International Journal of Research-GRANTHAALAYAH, Vol.5 Iss.6

3. Emmanuel Kwabena Anin, Isaac Ofori, Stephen Okyere, (2015), Factors Affecting Job Satisfaction of Employees in the Construction Supply Chain in the Ashanti Region of Ghana, European Journal of Business and Management, Vol.7, No.6, 2015, Kumasi, Ghana 
4. John S. Heywood and Xiangdong Wei, (2006), Performance Pay and Job Satisfaction; JIR 2006 48: 523; Australia

5. Robert Hoppock (1935) Job satisfaction, Harper and BrothersNew York and London

6. Spector, P. E., (1977) "Job satisfaction". Thousand Oaks, CA: Sage Publications, Inc. Australia

7. Wan Fauziah Wan Yusoff, Tan Shen Kian, Mohammad Talha Mohamed Idris, (2013), Herzberg's Two Factors Theory on Work Motivation: Does it Work for Today's Environment? G.J.C.M.P., Vol. 2(5):18-22. 